\title{
Frontline Nurses Experiences of the Covid-19 Pandemic - A Qualitative Study
}

\author{
Ahmed S. Alkarani ${ }^{1}$, Ahmed AbdElbagy Ibrahem² ${ }^{2}$ Hajar A. Alasmari³ ${ }^{3}$ Rzan A. Alghamdi ${ }^{4}$ \\ 1, 2, 3 Department of Nursing, Taif, Saudi Arabia, ${ }^{4}$ Registered at Saudi \\ Commission for Health Specialities, Saudi Arabia.
}

\section{ABSTRACT}

\section{BACKGROUND}

The coronavirus disease 2019 (COVID-19) pandemic had unquestionably caused a massive crisis worldwide. This pandemic had obstructed nearly all aspects of the population's lives and widely affected healthcare institutions, especially nurses, who are the frontline fighters of the pandemic. Their presence and duties are crucial in controlling the pandemic. Therefore, the study was done to explore the experiences of nurses in delivering healthcare throughout the pandemic and the objectives of this research were to a) explore the experience of frontline nurses during the COVID-19 pandemic, and b) to understand how COVID-19 had affected frontline nurses.

\section{METHODS}

This study is a qualitative study reviewed and approved by the Research Ethics Committee of Taif University, Saudi Arabia, under the application code: 42 - 174. The total number of participants were twenty-four nurses from King Faisal Medical Complex, Taif city, Saudi Arabia. The study conducted semi-structured interviews and the data was obtained via face time. The average time of the interview was between 40 and 60 minutes.

\section{RESULTS}

The results indicated two major themes. First, the negative effects of COVID-19 on nurses, which included fear of infection and transmission of the disease, challenging working conditions and a change in social lifestyle. The second theme is the positive impact of the Covid pandemic on nurses, which included increased awareness of the role of nursing in society, an increase in nurses' self-confidence and the strength of support from nursing directors.

\section{CONCLUSIONS}

COVID-19 has had an impact on nurses, both physically and mentally. They have struggled with factors surrounding their occupation and personal lives. It is well established that this pandemic has had more drawbacks than favourable outcomes with regard to nurses. Nevertheless, the funding and development that nurses obtained have improved their professional skills, experience and acceptance of future potential outbreaks.

\section{KEY WORDS}

Nurses Experience of COVID-19, A Qualitative Study, Saudi Arabia.
Corresponding Author: Dr. Ahmed S Alkarani, Assistant Professor in the Nursing Department, Faculty of Applied Medical Sciences, Taif University, Saudi Arabia King Fahad Ring Rd, Beside King Abdul Aziz Specialized Hospital, PO Box -2425 .

E-mail:asakg@live.com.

DOI: $10.14260 /$ jemds/2021/675

How to Cite This Article:

Alkarani AS, Ibrahem AA, Alasmari HA, et al. Frontline nurses experiences of the covid-19 pandemic - a qualitative study. $J$ Evolution Med Dent Sci 2021;10(38):33273332, DOI: 10.14260/jemds/2021/675

Submission 07-07-2021,

Peer Review 26-08-2021,

Acceptance 04-09-2021,

Published 20-09-2021.

Copyright (c) 2021 Ahmed S Alkarani et al. This is an open access article distributed under Creative Commons Attribution License [Attribution 4.0 International (CC BY 4.0)] 


\section{BACKGROUND}

The corona varus disease 2019 is a novel virus which emerged in China. The cases of this disease have since been reported across the nation. The World Health Organization (WHO) declared that the virus characterises as a public health pandemic. The is because COVID-19 is a transmitted disease which can produce certain clinical indications - such as high body temperature, heavy breathing and coughing 1 and these symptoms in many cases lead to hospitalisation. It is risky to all individuals, however, it can be deathly to those with underlying health conditions. It is recognised that there have been more than 184,000,000 cases worldwide of COVID-19.2 Likewise, the existence of this pandemic has impacted many legislations and procedures all around the world. For example, wearing masks and social distancing have become mandatory, as well as in many countries extended lockdowns have been implemented. This has negatively affected all aspects of life such as economy, education, and the governmental sectors. Consequently, many countries have introduced and promoted vaccinations, which can also allow many activities to return such as gatherings, flying overseas, and opening public sectors. Additionally, many governments have introduced national apps which are necessary to use when entering public places. This is to restrict social gatherings and manage the movements of infected people. Meanwhile, in Saudi Arabia the confirmed cases have reached over 496,000 and the WHO is expecting a further increase. ${ }^{3}$ Recently, the Saudi Arabian government has decided that only vaccinated individuals would be allowed to attend public sectors. Thus, most of the Saudi citizens are willing to be vaccinated in order to attend their jobs, schools, and other governmental sectors. These new legislations and procedures managed have decreased the COVID-19 cases and support health care sectors to regain control over the overwhelming COVID-19 cases. Throughout this pandemic, the existence of frontline nurses has been necessary to overcome the challenging cases of COVID-19 alongside other critically ill patients. ${ }^{4}$ They have effectively contributed in decreasing the COVID-19 cases by testing and treating the cases. Furthermore, the role of frontline nurses includes delivering essential care in the emergency department, working with suspected cases of COVID-19 with precautions, contributing to general nursing practice in managing numerous infections concurrently and playing a critical role in expanding services. ${ }^{5}$ Thus, during a crisis, nurses are expected to undertake additional roles. Therefore, health institutions have now started promoting health behaviours to the public to help in reducing the pressure on the front-line nurses. However, regardless of all the responsibilities and roles frontline nurses undertake, researchers have agreed that nurses do not receive the same acknowledgment as healthcare specialists in their own right and are only assumed as supplementary to doctors. ${ }^{6}$ Therefore, it is critical for nurses to be recognised, especially during the pandemic, as they are facing extreme levels of stress, depression, and anxiety. ${ }^{7}$ Hence, this qualitative research is aiming to a) investigate the advantages and disadvantages experienced by frontline nurses during the COVID-19 pandemic, and b) understand how COVID-19 had affected frontline nurses. The fundamental objective of this qualitative study is to find the key changes COVID-19 has brought to frontline nurses' performance, wellbeing and personal lives. This could result in enhancing the experience and welfare of healthcare providers, especially for future potential outbreaks.

\section{METHODS}

This qualitative study used semi-structured interviews. The study was conducted in the King Faisal Medical Complex, is a centre designed to receive COVID-19 patients in Taif, Saudi Arabia from May 2021 to June 2021. The target population were the nurses who provided care for COVID-19 patients in the King Faisal Medical Complex. Invitations were sent to all nurses working in intensive care unit (ICU), emergency room (ER) and wards at the King Faisal Medical Complex in Taif. The data gathered from nurses who passed the following inclusion criteria included willingness to be a research subject and having at least three months experience of providing care for coronavirus cases. There were 24 nurses in total participating in the study. The data was obtained by in-depth individual interviews. Semi-structured interviews were conducted via face time to prevent direct contact with nurses delivering care for confirmed cases. The average time of the personal interview was between 40 and 60 minutes. Thematic analysis used to analyse the data was gathered from the nurses. Furthermore, this research used the standard for reporting qualitative research (SRQR) to structure the study.

\section{Ethical Approval}

The Research Ethics Committee of Taif University, Saudi Arabia reviewed and approved this study under application code:42 - 174. The ethical considerations were adhered to, such as an information sheet and consent form, and anonymity and confidentiality were assured before the data was collected.

\section{Data Analysis}

All 24 semi-structured interviews were recorded and transcribed verbatim and the data was analysed by using thematic analysis.

\section{RESULTS}

The total number of participants who agreed to participate in this study and were subjected to the inclusion criteria were twenty - four nurses. Their ages were between 24 and 43 years, with an average age of 31 years. Among the participants, 15 were male nurses and 9 were female nurses. Majority of the participants had bachelor's degree in nursing and the participants were nurses working in intensive care units, emergency departments and medical surgical units. The range of nurses' experience was between 1 and 16 years, as indicated in Table 1 . This study indicated that $90 \%$ of the participants had taken the complete vaccine dose, and $10 \%$ had taken the first dose and were waiting for the second dose. The results of this study showed two major themes as follows: Negative effects of COVID-19 on nurses, which included: Fear of 
infection and transmission of the disease, challenges of working conditions and change of social lifestyle. The second theme is the positive impact of the COVID pandemic on nurses, which included: Increased awareness of the role of nurses among society, increased nurses' self-confidence and strength of nursing directors support.

\begin{tabular}{|cccccc|}
\hline Number & Age & Gender & Qualifications & $\begin{array}{c}\text { Place of } \\
\text { Work }\end{array}$ & Experiences \\
1 & 29 & M & BSN & ER & 4 \\
2 & 31 & M & BSN & ER & 6 \\
3 & 35 & M & BSN & ER & 10 \\
4 & 32 & M & BSN & MS & 7 \\
5 & 28 & M & BSN & MS & 4 \\
6 & 27 & M & BSN & MS & 3 \\
7 & 35 & M & BSN & ER & 9 \\
8 & 28 & M & Diploma & ICU & 3 \\
9 & 37 & F & BSN & ICU & 12 \\
10 & 39 & F & Diploma & ICU & 14 \\
11 & 32 & F & Diploma & ICU & 4 \\
12 & 28 & F & BSN & ICU & 2 \\
13 & 26 & F & BSN & ICU & 2 \\
14 & 25 & M & BSN & ICU & 1.5 \\
15 & 27 & M & BSN & ICU & 2 \\
16 & 35 & M & Diploma & ICU & 11 \\
17 & 38 & M & BSN & ICU & 16 \\
18 & 24 & M & BSN & ICU & 1 \\
19 & 30 & M & BSN & ER & 5 \\
20 & 31 & F & Diploma & ER & 7 \\
21 & 34 & F & Diploma & ER & 11 \\
22 & 28 & F & BSN & MS & 3 \\
23 & 35 & F & Diploma & MS & 12 \\
24 & 43 & M & Diploma & MS & 9 \\
\hline \multicolumn{7}{r}{} & Table 1. The Participant's Characteristics & \\
\hline & & & & & \\
\hline
\end{tabular}

The Negative Effects of Covid-19 on Nurses Fear of infection and transmission of the disease.

All participants indicated that COVID-19 disease was rapidly spreading in the population and the consequences of this is increased deaths and the large number of suspected patients. Therefore, most of them mentioned that although they are working with the protocols adopted to deal with this type of patients during this period, they stated that they were very scared of getting infected of COVID-19 and it is possible to transmit this disease to their families and friends, and this is what everyone would not like to happen, as quoted below -

'I was a new mother and I have a little boy, God protect him. You know what I did? I had to separate my son from me for almost 5 months because of my fear of Corona. I did not want to stay with him because I feared that he might catch an infection from me. God is the Protector' (Participant 13)

'One covid patient affected me more. He was a young man and he was not suffering from anything. Suddenly his condition relapsed to the worst and died, God's mercy upon him. I have fear. How young and strong guy suddenly died because this disease. So, I started thinking about myself and my family and who I can protect myself and them from me! OMG. You know how hard this feeling is?' (Participant 22)

'I worked hard to take all precautions to protect my family. I left my children with my parents in their house. I keep myself like an isolated patient after my duty? By God, I am under pressure and I think about those who are around me. You don't know, the disease may come to me, to you, we do not know. I was afraid that it would bring me the disease and transmit it to someone else' (Participant 9)

\section{Challenges of Working}

Since the beginning of the COVID 19 pandemic, the Saudi Arabia, represented by the Ministry of Health, has taken many rules and regulations in public and in health care facilities to stop the disease and limit its spread, such as the system of entry and exit from facilities, the protocol for dealing with patients and other precautionary rules. These rules and regulations had an impact on the working lifestyle of nurses and this means more effort, time, reports and overtime during the work period, as quoted below -

'We feel that we are being watched from the top of the organizational hierarchy, daily reports, daily follow-ups, daily checks, and daily pressure. For the patients, they need our services more than other patients because of their situation. They occupy the department more than other patients, and we spend extra time and effort than normal patients' (Participant 3)

'Covid patients already have severe psychological effect, and they need great psychological support from us than other patients, which is difficult for us. Sometimes it is difficult for us in some cases to deal with Covid patients because they do not fully cooperate with us in following the instructions for their health condition, and these are new challenges in our daily work in the hospital' (Participant 22)

\section{Change of Social Lifestyle}

The Saud government applied many restrictions such as limiting social gatherings, preventing curfews, and other things to control the disease spired. Although, these instructions and restrictions were to protect the society, however, it had an impact on the participant's usual social life and nurses have no choice except stay safe at home, as quoted below:

'I will be honest with you. This pandemic has had many effects on our social life, such as travelling and gatherings. And it has definitely affected me negatively by lack of meetings and family visits. You know how important it is to visit our parents' (Participant 1)

'Covid 19 was and still is definitely affecting my daily life. Because the society is now closed around itself. Therefore, the COVID-19 $100 \%$ affected me in many things such as social aspects and other aspects and this affected me' (Participant 19)

'Certainly, it had an impact on my life quality. For example, stopping of sports activities, family visits restricted and others. All these changes affect our social lifestyle. and as all know, that our life is dependent on social gathering' (Participant 15)

\section{The Positive Impact of COVID-19 on Nurses}

Several participants mentioned that despite the difficulties they faced in daily work during the COVID-19 pandemic, including work pressure and fear of infection and other things. It also has had positive effects on them. For example, increased awareness of nursing role among the society, increase nurses' self-confidence and continuing of nursing directors support. All this is likely to positively affect the future of nursing.

Increased nursing role awareness among society 'Despite its negative aspects, it has some positive aspects?! Yes, this pandemic made positive changes in society towards my career. They called us as nursing heroes because we are in the frontline of defence from the infectious disease. Thanks to God' 


\section{(Participant 4)}

'I love working in nursing since the beginning of my study, but society, with this crisis, has changed obviously its perception of health practitioners in general and nurses in particular. So that it has increased respect and considered it really an important specialty' (Participant 23)

Increase nurses' self - confidence

'We feel completely satisfied and confident when we can help and make a positive change in the lives of patients. Of course, at the beginning, there were difficulties and lack of clarity, but thank God, with the passage of time, learning and adapting to the situation was a beautiful thing through which I was able to help sick people and protect myself and my family' (Participant 11)

'Frankly speaking, COVID-19 has a positive effect, since you are in the first row to confront this virus and to help patients, and your work is in the media daily news. Yes, there were some difficulties, and we overcomed, praise be to God, and thus you feel confident in work which inturn increases happiness and satisfaction' (Participant 2)

\section{Strength of Nursing Director's Support}

'In this pandemic, the nursing administration played a significant role. We have been prepared by joining specific programs and courses for infection control and how to deal with infectious disease patients in general and corona in particular' (Participant 24)

'In fact, after intensive courses and conferences for us from the nursing administration about everything, I wanted to know about the disease, I knew it, and now I have enough experience to deal with Covid patients in addition to that I have been given instructions that I can limit this disease. And it was a great work of them, it will remain even after this pandemic disappear' (Participant 12)

\section{DISCUSSION}

Worldwide, healthcare workers are the frontline fighters of the COVID-19 pandemic disaster. Their presence is key to overcoming the pandemic in the safest way possible. Therefore, this research has investigated their experience during COVID-19. In this study, it was found that frontline nurses have experienced many psychological and physical challenges during the pandemic. It is proven that the spread speed of COVID-19 was extraordinarily fast. ${ }^{8}$ Consequently, frontline nurses have expressed their concern about, and fear of, becoming infected and transmitting COVID-19 to patients, family, or friends. This indictor has introduced enormous physiological pressures on nurses. It was also found by Basit et al. ${ }^{9}$ that frontline nurses have suffered from extreme psychological pressure due to lack of personal protective equipment to support them in reducing the spread of the disease. According to Shechter et al. ${ }^{10}$ these psychological pressures have led to mental health problems, such as stress, anxiety and depression. Hence, these complications will impact negatively on nurses' functioning, as well as on their personal lives. Likewise, frontline nurses in many countries have undergone psychological complications owing to the pressures and distress of the pandemic. On the other hand,
Chen et al. ${ }^{11}$ stated that undergoing these psychological pressures can result in increasing self-confidence, education, professional knowledge and skills. Similarly, other studies have shown that nurses' decisions to proudly face the COVID19 outbreak and endure these difficulties has enhanced their emotional intelligence and stress coping mechanisms. ${ }^{12}$ Furthermore, the results of this study have also presented many physical challenges. These mostly revolved around the work lifestyles of nurses, as they were forced to change. For example, the alterations in organising the admissions and departures from facilities, alongside the newly introduced procedures for dealing with patients and their families. These challenges were also found in the study by Galehdar et al. ${ }^{13}$ as nurses have experienced frustration and dissatisfaction due to the disadvantages and difficulties these new systems have brought, to their work and to their patients. Nurses have become frustrated due to the unpredicted change in work schedules. These findings are in line with the results of Rzymski et al. ${ }^{14}$ as it explained that nurses' unpredicted working schedules have resulted in sleep deprivation, inability to concentrate, excessive fatigue and insomnia. This study has found that their performance can be impacted due to poor physical health. Moreover, because of the pandemic, policies and legalisation were introduced worldwide, such as social distancing, curfews and mandatory wearing of masks. Accordingly, societies have continued to follow these restrictions, even when cases were decreasing. ${ }^{15}$ Nurses were also prevented from having a social life, and relieving their stress. In fact, many studies have proved that social gatherings had an impact on people's welfare. Therefore, the distancing has caused extreme health issues and damaged the wellbeing of more than half the population, including nurses. ${ }^{16}$ Likewise, social distancing has also impacted their education and work strategies. ${ }^{17}$ Unlike other professions, nurses have found it impossible to implement social restriction with patients. Zolnikov et al.18 has shown that these restrictions have affected the ability to understand patients in work settings. They have also made it difficult for health workers to diagnose and treat patients. Furthermore, studies have also shown the impact of not being able to implement social distancing along with the wider population, which caused nurses to feel uneasiness and discomfort. Similarly, nurses also expressed concerns about uncertain work schedules. Significantly, due to the implementation of curfews, nurses were at risk of breaking the law. ${ }^{19}$ On the other hand, participants in this study have shared many advantageous experiences due to the pandemic. This study has found that there was an increase in nurses' role awareness. Participants in this study explained that society has changed their perception and view of healthcare workers. This finding affirms a previous study implemented in Saudi Arabia, where it was found that nurses had experienced positive behaviours and awareness when it came to their role during the outbreak. ${ }^{20}$ According to Harwood, ${ }^{21}$ the pandemic has had a positive impact on how health organisations can be improved and acknowledged. Additionally, the positive impact of the pandemic also extends to nurses' resumes and work experience. Their presence in the outbreak has led to awareness of their roles among directors and higher health professionals. Gradually, nurses have gained major support from directors to overcome the pandemic efficiently. Participants have also expressed an increase in self-confidence and gaining of outstanding professional knowledge. This is in 
line with the finding of Gao et al. ${ }^{22}$ which indicates that nurses have shared a constructive outcome of the pandemic.

\section{CONCLUSIONS}

In conclusion, the outbreak of this pandemic has impacted many jobs worldwide, specifically frontline nurses. Therefore, this study has explored the frontline nurses' experience during the pandemic. The study gathered 24 participants from a wide spectrum of ages and interviewed them about their experiences during the pandemic. It was found that the outbreak had major physical and mental impacts on nurses. The nurses have mainly struggled with the countless factors surrounding their profession and work implementation. It is recognised that this pandemic had more disadvantages than positive outcomes for nurses. However, the support and development that nurses received have enhanced their professional skills, experience and knowledge. Consequently, this has improved nurses' readiness for future potential outbreaks.

\section{Limitations of This Study}

This study has experienced few limitations. Firstly, the duration of this study was condensed and the pandemic is ongoing. Thus, participants could go through further experiences. Secondly, the location of participants in this study was a single city

Data sharing statement provided by the authors is available with the full text of this article at jemds.com.

Financial or other competing interests: None.

Disclosure forms provided by the authors are available with the full text of this article at jemds.com.

\section{REFERENCES}

[1] Okuyan CB, Begen MA. Why are elderly at higher risk and what should be done for them During the COVID - 19 pandemic? International Journal of Caring Sciences 2021;14(1):767.

[2] Kaiser Family Foundation. COVID-19 Coronavirus Tracker. KFF: 2021 [updated 2021 Jul 7: cited 2021 Jul 8]. https://www.kff.org/coronavirus-covid-19/factsheet/coronavirus-tracker/

[3] World Health Organization. Global: Saudi Arabia Situation. WHO Health Emergency Dashboard: WHO (COVID - 19) Homepage, 2021 [updated 2021 Jun 26: cited 2021 Jul 8]. https://covid19.who.int/region/emro/country/sa.

[4] Kholis AH, Hidayah N, Priyanti RP, et al. Snapshot of nurse readiness for the covid - 19 pandemic in indonesia: a qualitative study. KnE Life Sciences 2021;6(1):310-22.

[5] Al Thobaity A, Alshammari F. Nurses on the frontline against the COVID-19 pandemic: an integrative review. Dubai Medical Journal 2020;3:87-92.

[6] Sethi A, Aamir HS, Sethi BA, et al. Impact on frontline nurses in the fight against coronavirus disease. Annals of King Edward Medical University 2020;26(Special Issue):120-5.
[7] Lee N, Lee HJ. South Korean Nurses' experiences with patient care at a covid - 19 - designated hospital: growth after the frontline battle against an infectious disease pandemic. International Journal of Environmental Research and Public Health 2020;17(23):9015.

[8] Karim R, Chowdhury FN, Rafi TH. Environmental and Earth Sciences Research Journal: Journal homepage 2021;8(1):23-36. http://iieta.org/journals/eesrj.

[9] Basit M, Peni MR. Psychological stress of nurses during the Covid-19 pandemic. KnE Life Sciences 2021;6(1):25667.

[10] Shechter A, Diaz F, Moise N, et al. Psychological distress, coping behaviors and preferences for support among New York healthcare workers during the COVID-19 pandemic. General Hospital Psychiatry 2020;66:1-8.

[11] Chen SH, Liu JE, Bai XY, et al. Providing targeted psychological support to frontline nurses involved in the management of COVID-19: an action research. Journal of Nursing Management 2021;29(5):1169-79.

[12] Munawar K, Choudhry FR. Exploring stress coping strategies of frontline emergency health workers dealing Covid - 19 in Pakistan: a qualitative inquiry. American Journal of Infection Control 2021;49(3):286-92.

[13] Galehdar N, Toulabi T, Kamran A, et al. Exploring nurses' perception about the care needs of patients with COVID19: a qualitative study. BMC Nursing 2020;19(1):119.

[14] Rzymski P, Mamzer H, Nowicki M. The main sources and potential effects of COVID-19-related discrimination. Advances in Experimental Medicine and Biology 2021;1318:705-25.

[15] Abd Elbagy A, Alkarani AS. Response to the precautionary measures to prevent coronaviruses - 19: after decline of the pandemic, Taif City, KSA. Journal of Public Health Research and Development 2021;12(3):294-301.

[16] Geirdal AØ, Ruffolo M, Leung J, et al. Mental health, quality of life, wellbeing, loneliness and use of social media in a time of social distancing during the COVID-19 outbreak. A cross-country comparative study. Journal of Mental Health 2021;30(2):148-55.

[17] AlKarani AS, Thobaity AA. Medical staff members' experiences with blackboard at Taif University, Saudi Arabia. Journal of Multidisciplinary Healthcare 2020;13:1629-34.

[18] Zolnikov TR, Furio F. First responders and social distancing during the COVID-19 pandemic. Journal of Human Behavior in the Social Environment 2021;31(14):244-53.

[19] Cuvadar A. Factors and management of nurses affecting the control perception during Covid-19 outbreak. International Journal of Caring Sciences 2020;13(2):1460-2.

[20] Al - Dossary R, Alamri M, Albaqawi H, et al. Awareness, attitudes, prevention, and perceptions of COVID-19 outbreak among nurses in Saudi Arabia. International Journal of Environmental Research and Public Health 2020;17(21):8269-85.

[21] Harwood L. Pandemic uncertainty: considerations for nephrology nurses. Nephrology Nursing Journal 2020;47(2):127-30. 
[22] Gao X, Jiang L, Hu Y, et al. Nurses' experiences regarding shift patterns in isolation wards during the COVID-19 pandemic in China: a qualitative study. Journal of Clinical Nursing 2020;29(21-22):4270-80. 